\title{
(6) OPEN ACCESS \\ Impact of a child stimulation intervention on early child development in rural Peru: a cluster randomised trial using a reciprocal control design
}

\author{
Stella Maria Hartinger, ${ }^{1,2,3,4}$ Claudio Franco Lanata, ${ }^{3}$ Jan Hattendorf, ${ }^{1,2}$ \\ Jennyfer Wolf, ${ }^{1,2}$ Ana Isabel Gil, ${ }^{3}$ Mariela Ortiz Obando, ${ }^{5}$ Magaly Noblega, ${ }^{6}$ \\ Hector Verastegui, ${ }^{3,4}$ Daniel Mäusezahl ${ }^{1,2}$
}

\begin{abstract}
- Additional material is published online only. To view please visit the journal online (http://dx.doi.org/10.1136/jech2015-206536)

${ }^{1}$ Department of Epidemiology and Public Health, Swiss Tropical and Public Health Institute, Basel, Switzerland ${ }^{2}$ University of Basel, Basel, Switzerland

${ }^{3}$ Instituto de Investigación Nutricional, Lima, Perú

${ }^{4}$ Universidad Peruana Cayetano Heredia, Lima, Perú

${ }^{5}$ Programa Nacional CUNA

MAS, Lima, Perú

${ }^{6}$ Pontificia Universidad Católica del Perú, Lima, Perú
\end{abstract}

Correspondence to Dr Daniel Mäusezahl, Department of Public Health and Epidemiology, Swiss Tropical and Public Health Institute, Socinstr. 57, Basel 4051, Switzerland; Daniel. Maeusezahl@unibas.ch

Received 21 August 2015 Revised 29 July 2016 Accepted 29 July 2016 Published Online First 9 September 2016

\section{CrossMark}

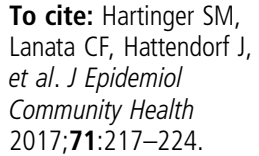

\section{ABSTRACT}

Objective Stimulation in early childhood can alleviate adverse effects of poverty. In a community-randomised trial, we implemented 2 home-based interventions, each serving as an attention control for the other. One group received an integrated household intervention package (IHIP), whereas the other group received an early child development (ECD) intervention. The primary objective of the study was to evaluate the effect of IHIP on diarrhoea and respiratory infections, the details of which are described elsewhere. Here, we present the impact of the ECD intervention on early childhood development indicators.

Methods In this non-blinded community-randomised trial, an ECD intervention, adapted from the Peruvian government's National Wawa Wasi ECD programme, was implemented in 25 rural Peruvian Andean communities. We enrolled 534 children aged 6-35 months, from 50 communities randomised 1:1 into ECD and IHIP communities. In ECD communities, trained fieldworkers instructed mothers every 3 weeks over the 12 months study, to stimulate and interact with their children and to use standard programme toys. IHIP communities received an improved stove and hygiene promotion. Using a nationally validated ECD evaluation instrument, all children were assessed at baseline and 12 months later for overall performance on age-specific developmental milestones which fall into 7 developmental domains. Findings At baseline, ECD-group and IHIP-group children performed similarly in all domains. After 12 months, data from 258 ECD-group and 251 IHIPgroup children could be analysed. The proportion of children scoring above the mean in their specific age group was significantly higher in the ECD group in all domains (range: $12-23 \%$-points higher than IHIP group). We observed the biggest difference in fine motor skills ( $62 \%$ vs $39 \%$ scores above the mean, OR: 2.6 , 95\% Cl 1.7 to 3.9).

Conclusions The home-based ECD intervention effectively improved child development overall across domains and separately by investigated domain. Homebased strategies could be a promising component of poverty alleviation programmes seeking to improve developmental outcomes among rural Peruvian children. Trial registration number ISRCTN28191222; results.

\section{INTRODUCTION/BACKGROUND}

Opportunities for play, exploration and learning provided to young children critically shape their health and development throughout their lifetime. ${ }^{1}$ However, children around the globe are exposed to accumulated risks such as poverty, and challenging social and physical environments that limit the degree of stimulation offered by caregivers and the home environment. It was estimated that, worldwide, around 200 million children under 5 years of age do not develop to their full cognitive potential. $^{2}$ This has lifelong implications and adverse consequences for education, income, health, fertility rates and delinquency and jeopardises the development and well-being of future generations. ${ }^{3}$

Early childhood is a very important time for brain development, which comprises physical, socio/emotional and language/cognitive development. ${ }^{4} 5$ Brain development depends on many interacting and interdependent factors, such as genetic inheritance, health and nutritional status, quality of maternal-child interaction and environmental characteristics. ${ }^{6}$ Neuroplasticity, meaning the brain's ability to change in response to exogenous stimuli, is greatest during the first 3 years of life. $^{5}$

Early child development (ECD) interventions are usually seen as cost-effective and promising strategies for reaching children at-risk and for influencing success and productivity up to adult age..$^{7-9}$ The circumstances of poor households often result in less stimulation, parent-child interaction and stability. Poorer families are less likely to send their children to centre-based care. ${ }^{10}$ Similarly, deprivation in early childhood is believed to negatively affect IQ development, which affects other ECD markers, such as motor skills. ${ }^{11}$ Home-based interventions can help to alleviate the negative effects of poverty on child development, thereby preventing a widening of the gap between rich and poor. ${ }^{9}$

Peru has experienced strong economic growth in recent years, yet large inequalities persist. Nearly half of the children in the poorest income quintile are chronically malnourished compared to only $5 \%$ in the wealthiest income quintile. ${ }^{12}$ Overall, $18 \%$ of children below age 5 are stunted, $13 \%$ and $27 \%$ of households have no access to an improved water source or improved sanitation facility, respectively, and $34 \%$ use solid fuels for cooking and heating. ${ }^{3}$ A recent evaluation of 1900 Peruvian children found a large gap in cognitive development between the highest and the lowest socioeconomic group (assessed with a standard vocabulary test, Peabody Picture Vocabulary Test). ${ }^{14}$ This trend is 
also shown in the Programme for International Student Assessment, PISA, which ranked Peru last among 65 countries. ${ }^{15}$

Substantial differences exist between urban and rural areas. Measures of poverty and extreme poverty, infant mortality, chronic malnutrition, poor school performance and illiteracy are much higher in rural compared to urban areas. ${ }^{16} 17$ Rural Peruvian children in the poorest wealth quintile scored $>2$ SDs below the reference population in the applied standard vocabulary test. ${ }^{14}$ In our study area, San Marcos, Cajamarca, 25\% of the rural population was illiterate and $24 \%$ reached preschool level only, in 2007. ${ }^{18}$

Several countries in Latin America are focusing on ECD as a means of equalising opportunities early in life. ${ }^{12}$ In 1993, Peru created the Wawa Wasi National Programme (PNWW) to promote ECD in mostly urban day-care centres. ${ }^{19}$ A previous evaluation of the PNWW showed that the programme provided safe playing and learning environments for children and enabled mothers to work or study. ${ }^{19}$ Neither the PNWW nor its general approach has been evaluated in a randomised way. Our approach is unique as we used the approach of a national programme (the PNWW) and adapted it from application in urban day-care centres to the rural setting and the home environment which can greatly influence early child neurodevelopment. ${ }^{20}$

We designed a community-randomised trial with two different home-based interventions, whereby each intervention served as a control for the other to counteract bias associated with attention (ie, comparable interaction with the field teams in both groups), positive expectations and non-blinding. One group received the adapted PNWW ECD intervention, while the other received an integrated household intervention package (IHIP). The primary objective of the trial was to assess the effectiveness of the IHIP, comprising a ventilation-improved cookstove, running water and sink in the kitchen, a solar-based household drinking water treatment and a kitchen hygiene intervention. ${ }^{21}$ The initial main objective of the ECD intervention was to provide the control group with an intervention ensuring the same level of attention as the IHIP group, but unlikely to affect diarrhoea or respiratory infections. We evaluated study children on ECD 1 year after implementation. We assessed participating children for ECD markers at the onset of the study and at 1 year after implementation. In this article, we report on the impact of the ECD intervention on seven domains of ECD, including basic habits, personal and social development, gross motor skills, fine motor skills, relationship between objects, space and time, and communication, and compare those to the control group, which consisted of children from households receiving the IHIP.

\section{METHODS}

\section{Study site and design}

The study was conducted in 50 rural communities in the Cajamarca region, San Marcos province, in the northern highlands of Peru, between September 2008 and January 2010. Detailed information about the setting, sample size calculation, randomisation and the different interventions can be found elsewhere. ${ }^{21-23}$

From an initial 56 communities identified through a census and in compliance with the inclusion criteria, 5 communities did not have a sufficient number of children (fewer than 4) and 3 of those were joined to adjacent communities; the other 2 were excluded because of remoteness. We, hence, randomised 51 communities (one community was ultimately lost to follow-up) with eligible households (ie, having a child aged 635 months, using solid fuels as main energy source for cooking and not connected to a public sewage system) to the IHIP intervention ( 25 communities) or to the ECD intervention (25 communities), using covariate-based constrained randomisation. ${ }^{24}$ The IHIP group, consisting of 251 households, received an improved cookstove, kitchen sink, solar drinking water treatment and hygiene education. The other group, consisting of 258 households, received the ECD intervention as an alternative to reduce non-blinding bias and drop-out rates. ${ }^{25}{ }^{26}$ For the ECD intervention, we adapted the PNWW urban day-care centre scheme jointly with the programme staff and experts for application at rural household level. The adaptations for addressing a single child at home (as opposed to a group of children in a central day care) included: (1) not providing day care, (2) training individual mothers rather than day care staff, (3) providing a new set of toys and materials every 2 months and (4) providing 20-30 min sessions at home every 3 weeks, during which a field worker would ask the mother to play and interact with the child and offer additional guidance when needed. The main components of the PNWW were maintained: field workers encouraged early child stimulation through increased mother-child interaction, introduced stimulating toys and learning material adapted to the child's age and instructed mothers how to use the toys and how to create safe playing environments for their children. For the remainder of this article, we refer to the group receiving the early child education intervention as the 'ECD group' and to the group receiving the home-based environmental intervention package as the 'IHIP group'.

\section{Implementation of the ECD intervention}

The ECD intervention was implemented in 258 households in 25 communities with at least one child aged 6-35 months. Four field personnel, all preschool teachers, were trained before implementation for 5-6 hours at a Wawa Wasi centre. Specialised personnel trained the team in the correct use of the toys, learning materials and evaluation techniques. The team was responsible for implementing, promoting and evaluating the intervention.

The field personnel subsequently trained mothers to play, interact with and stimulate their children using the Wawa Wasi toys and learning materials provided. Mothers were encouraged to engage with their child at least $30 \mathrm{~min}$ every day and were asked to record the child's progress. Each mother received a 45 min training at baseline and follow-up trainings every 3 weeks (for 20-30 min, depending on the mother's needs) during the study. The interventions were delivered to households over a 12-month follow-up period, before final evaluation. Every 2 months, mothers were complimented for playing with their children and given the next set of toys, corresponding to the child's age. In total, each child received six sets of five toys.

\section{Evaluation of the ECD intervention}

ECD markers were assessed at baseline and at the end of the follow-up period for all children in the ECD and the IHIP groups. We used the nationally validated ECD evaluation instrument (referred to as 'lista de cotejo' or the 'checklist'), created for and used by the PNWW. The instrument has been originally assessed for content validity by a PNWW-expert panel for each specific developmental area. ${ }^{27}$ We, hence, chose this instrument to increase the policy relevance of our results. The instrument relies on directly observing the child completing the assessment tasks and does not rely on parent-reporting. Test-retest reliability cannot be assessed given that the 
evaluation process is itself a formative process for the child. We used a revised version of the checklist provided by the PNWW Cajamarca regional office, consisting of 180 indicators categorised into three main developmental areas and assessing seven development domains (the full checklist can be obtained from the corresponding author). ${ }^{28}$ The checklist uses a different set of indicators for each of the following age groups: 6-9, $9-12,12-18,18-24,24-36$ and $36-48$ months. The three main developmental areas-'My personal and social world', 'I learn while playing' and 'We talk' - were further divided into seven domains, including (1) development of basic habits, (2) personal and social development, (3) gross motor skills, (4) fine motor skills, (5) relationship between objects, (6) space and time, and (7) communication, which served as outcome measures.

The operational definitions for 'My personal and social world' consist of (1) the development of basic habits such as personal hygiene, nutrition, rest and play and (2) personal and social development through knowledge and appreciation of the own body, expression of emotions and feelings, name recognition and relationships with other people. 'Learn while playing' is defined as the development of (3) gross motor skills, that is, coordination and control of the body and thus the development of security, speed and accuracy in performing tasks of daily living and playing, (4) fine motor skills, that is, the progressive development of increasingly complex skills for more proficient tasks of daily living and playing, (5) the relationship between objects, that is, the cognitive development that allows children to establish the characteristics of and relationships between objects in their immediate environment and (6) space and time, that is, the acquisition of spatial concepts based on the child's body and objects and a temporal understanding based on his/her daily routine. 'We Talk' examines (7) communication in terms of verbal and nonverbal expressive and receptive language. It includes the development of graphical representations of communication such as imitation, role-playing games and music, which help to develop the ability to communicate thoughts, emotions, needs and interests. ${ }^{28}$

Each domain is assessed with a certain number of dichotomous indicators, using prompts, observations, specific evaluation toys or materials (eg, stacking and shape sorting, colour blocks, puzzles, picture cards, books and lace shape toys). One evaluation using the PNWW checklist took 30-40 min. Overall performance, that is, the proportion of assessment tasks successfully completed, was considered as the primary outcome and the proportion of assessment tasks completed by each of the seven domains as secondary outcomes in the evaluation of the ECD intervention.

\section{Statistical analysis}

Our outcome measures (the seven development domains) were converted into the dichotomous variable, 'scoring above the age-specific mean performance'. A child was judged as performing above the mean if he or she met a higher proportion of indicators in a certain category than the mean proportion met by all children in this age category. This calculation was performed separately for the baseline and 12-month follow-up assessments. The PNWW age categories were used (6-9 months, 912 months, $1-1.5$ years, $1.5-2$ years, $2-3$ years and $3-4$ years). Statistical analysis was performed using generalised estimating equation models with binary outcome and log link function, to account for correlation within villages. The intervention was included as the sole predictor in the statistical model. We included only children with complete baseline and follow-up assessment data in the model, that is, missing data were not imputed. All analyses were performed using the statistical software environment $\mathrm{R}$ (V.3.0.2).

\section{Ethics}

The study was approved by the Nutritional Research Institute (IIN, Instituto de Investigación Nutricional) Ethical Review Board in Peru and by the Swiss cantonal ethical review board of Basel, Switzerland (Ethikkommission Beider Basel, EKBB).

\section{RESULTS}

Of the 56 communities initially identified in the study area, 51 were eligible for randomisation (1 community refused the offer to participate). In 25 IHIP-intervention communities, 267 of 414 screened children met the age and household inclusion criteria, while 267 of 451 met the criteria in the 25 ECD-intervention communities. Baseline assessments were obtained from families that met the inclusion criteria, agreed to participate and signed the informed consent. This resulted in 251 IHIP-group and 258 ECD-group children available for follow-up. Of these, 219 IHIP-group children and 216 ECD-group children completed the final assessment (figure 1). Losses to follow-up were mainly due to withdrawal and out-migration.

At baseline, children in ECD and IHIP communities were comparable in terms of sex, age and socioeconomic factors (table 1). The mean age of the children was 2 years and about half of them were females. The proportion of assessment tasks successfully completed was also balanced in both groups (detailed results are presented in online supplementary figure S1 and cluster-level results are presented in online supplementary figure S2). Baseline characteristics stratified by loss to follow-up are presented in the online supplementary table S1. Additional details are provided elsewhere. ${ }^{21}$

After 1 year, the median proportion of assessment tasks successfully completed was $65 \%$ in the ECD group (IQR: $50-77 \%$ ) compared to $51 \%$ (IQR: $39-64 \%$ ) in the IHIP group. Figure 2 shows the changes in the proportion of successfully completed assessment tasks for ECD and IHIP groups, from baseline to final assessment 12 months later. Though similar at baseline (dashed lines), performance of the ECD group (grey solid line) at follow-up is higher than performance of the IHIP group; the latter showing only minor changes compared to baseline (black solid line). At the final assessment at follow-up the mode of the overall successfully solved tasks, ie the peak of the density lines, was $72 \%$ in the ECD group compared to $55 \%$ in the IHIP group. Compared to the baseline assessment, the number of children completing about $80 \%$ of the tasks increased. Furthermore, children from ECD communities performed better in all seven domains (figure 3). Likewise, with respect to the outcomes-proportion of children scoring above the mean -we observed the biggest difference in the domain of fine motor skills. Sixty-two per cent of children scored above average in the ECD group, but only $39 \%$ of children had above average score in the IHIP group (RR: 1.6, 95\% CI 1.2 to 2.0). The smallest difference was in the gross motor domain $(49 \%$ vs $37 \%$, RR: $1.3,95 \%$ CI 1.0 to 1.7$)$. The better performance among the ECD-group children versus the IHIP-group children was statistically significant in all seven domains (table 2). Note that the mean score is calculated separately for each age category, so improvements between baseline and follow-up do not merely indicate improvements associated with older ages. Descriptive results on cluster level are presented in online supplementary figure S2. 
Figure 1 Flow chart. ECD, early child development; IHIP, integrated home-based intervention package.

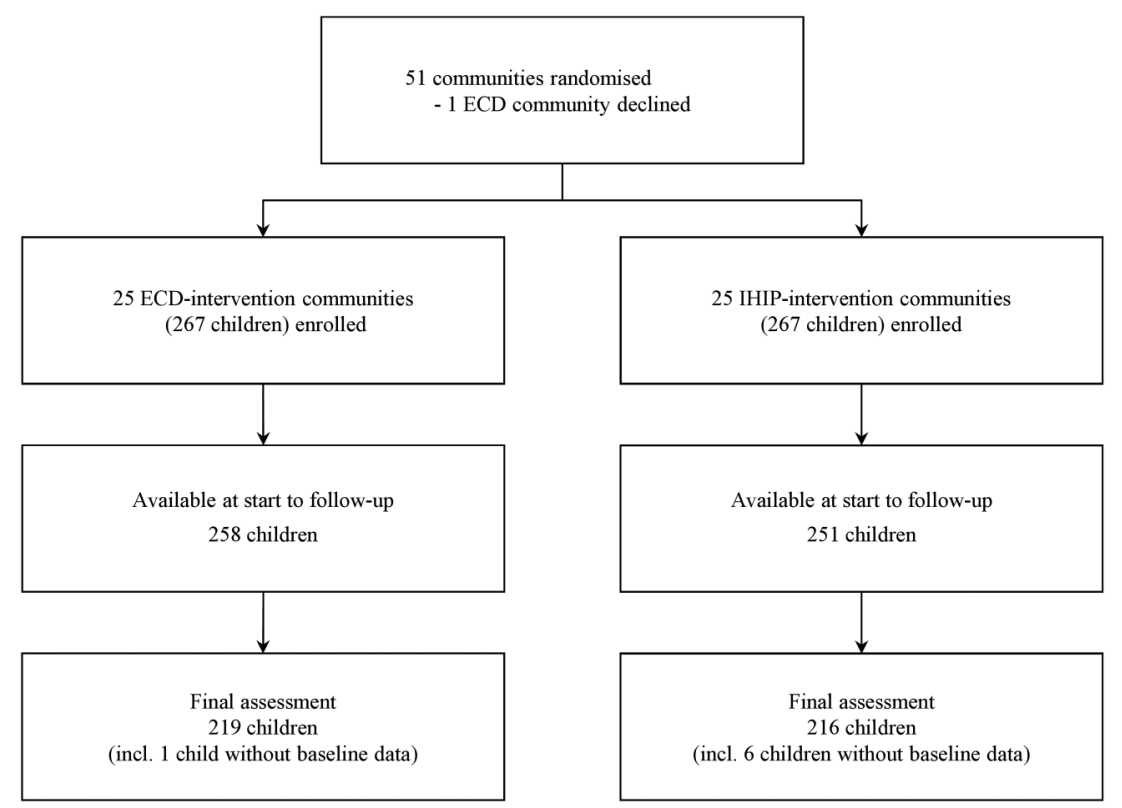

Table 1 Baseline characteristics of the IHIP and ECD group

\begin{tabular}{|c|c|c|c|c|}
\hline & \multicolumn{2}{|c|}{ IHIP group } & \multicolumn{2}{|c|}{ ECD group } \\
\hline & $\mathrm{N}$ & $\begin{array}{l}\text { Mean (SD) or } \\
\%\end{array}$ & $\mathrm{~N}$ & $\begin{array}{l}\text { Mean (SD) or } \\
\%\end{array}$ \\
\hline \multicolumn{5}{|l|}{ Demography } \\
\hline Number of household members & 226 & $5.0(1.6)$ & 234 & $4.6(1.5)$ \\
\hline Age of children (years) & 266 & $2.0(0.7)$ & 266 & $2.0(0.7)$ \\
\hline Age of caretaker (years) & 217 & $30(7.8)$ & 223 & $29(7.7)$ \\
\hline Sex of children (female) & 267 & $47 \%$ & 266 & $49 \%$ \\
\hline Household assets & 226 & & 234 & \\
\hline Piped water to house or yard & & $79 \%$ & & $78 \%$ \\
\hline Lighting & & $27 \%$ & & $26 \%$ \\
\hline Latrine & & $55 \%$ & & $54 \%$ \\
\hline Earthen floor & & $98 \%$ & & $98 \%$ \\
\hline Roof tiles & & $96 \%$ & & $98 \%$ \\
\hline Adobe wall & & $97 \%$ & & $98 \%$ \\
\hline Radio & & $90 \%$ & & $87 \%$ \\
\hline Television & & $23 \%$ & & $20 \%$ \\
\hline \multirow[t]{2}{*}{ Mobile phone } & & $26 \%$ & & $32 \%$ \\
\hline & & Median (IQR) & & Median (IQR) \\
\hline Development assessment & 258 & & 251 & \\
\hline Proportion of indicators solved & & $46 \%(34-60)$ & & $47 \%(38-57)$ \\
\hline \multicolumn{5}{|l|}{ Proportion solved of indicator } \\
\hline Basic habits & & $50 \%(33-67)$ & & $50 \%(33-67)$ \\
\hline $\begin{array}{l}\text { Personal and social } \\
\text { development }\end{array}$ & & $67 \%(40-80)$ & & $67 \%(50-83)$ \\
\hline Gross motor skills & & $60 \%(40-100)$ & & $63 \%(50-80)$ \\
\hline Fine motor skills & & $40 \%(20-50)$ & & $33 \%(20-60)$ \\
\hline Relationship between objects & & $50 \%(33-67)$ & & $50 \%(33-67)$ \\
\hline Space and time & & $33 \%(0-50)$ & & $33 \%(0-50)$ \\
\hline Communication & & $40 \%(0-67)$ & & $40 \%(0-67)$ \\
\hline
\end{tabular}

Figure 4 presents how performance at baseline translates into performance at follow-up. The ECD intervention showed a positive impact in all children, including those exhibiting a poor performance at baseline. Of the $26 \mathrm{ECD}$-group children who

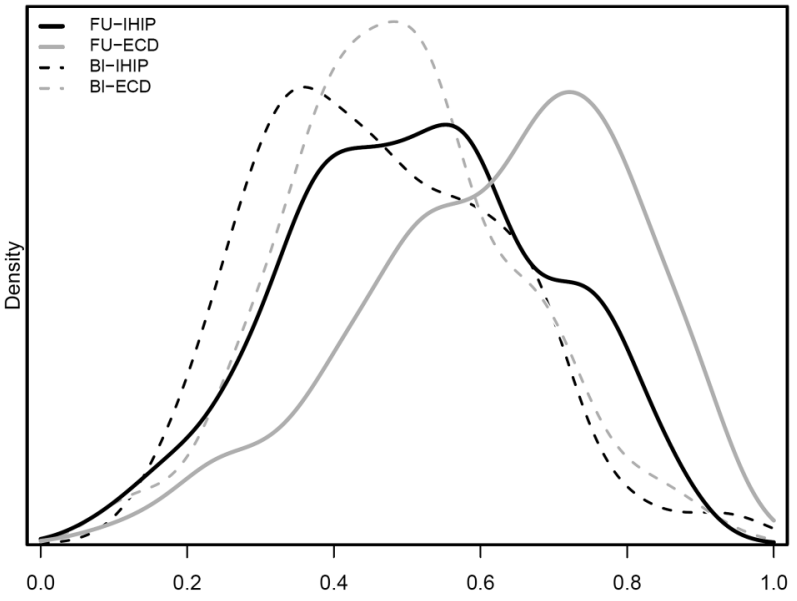

Figure 2 Distribution (density plot) of the proportion of successfully completed ECD assessment tasks at baseline and final assessment. Grey line represents ECD group at baseline (dashed) and final assessment (solid); black line represents IHIP group at baseline (dashed) and final assessment (solid) after 1 year. ECD, early child development; IHIP, integrated home-based intervention package.

completed fewer than $30 \%$ of all assessment tasks at baseline, only $3(12 \%)$ remained in this category. More than threequarters of them were able to solve $>50 \%$ of the tasks at final assessment. About $60 \%$ from each of the other performance categories (ranging from $30 \%$ to $60 \%$ of assessment tasks successfully completed at baseline) belonged to the best performing category ( $>60 \%$ of assessment tasks successfully completed) at the time of final assessment.

\section{DISCUSSION}

Children who received the ECD intervention adapted for rural household-level application (from the Peruvian PNWW programme) significantly improved in overall performance and separately by domain in all seven developmental assessment domains (basic habits, personal and social development, gross motor skills, fine motor skills, relationship between objects, space and time, and communication), compared to children 


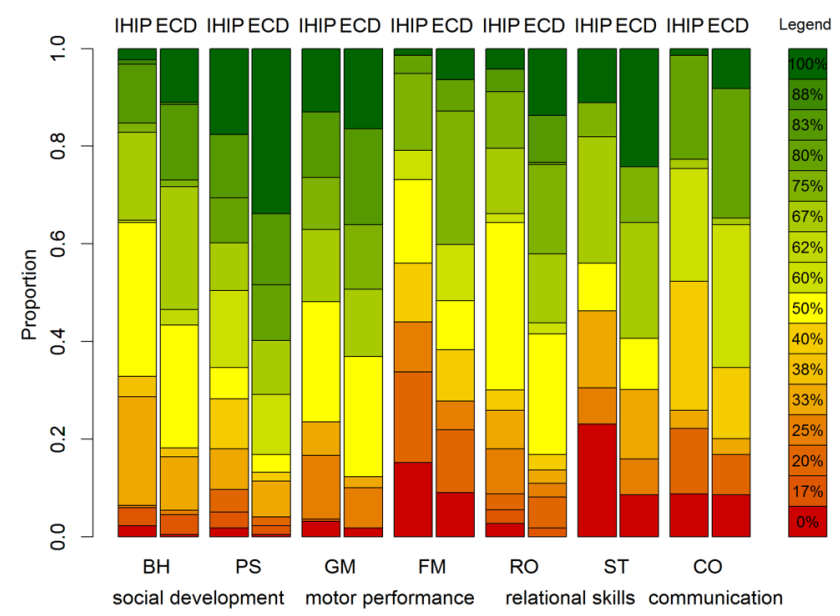

Figure 3 Percentage of ECD assessment tasks successfully completed at final assessment by proportion of children in ECD or IHIP group separated by the seven development domains. The scale on the left indicates the proportion of children. The legend on the right indicates using colour-coding the percentage of tasks fulfilled by children in the ECD or IHIP group and separated by the seven development domains. $\mathrm{BH}$, basic habits; $\mathrm{CO}$, communication; $\mathrm{ECD}$, early child development; FM, fine motor skills; GM, gross motor skills; IHIP, integrated home-based intervention package; PS, personal and social development; RO, relationship between objects; ST, space and time.

who received the environmental intervention. It has been shown previously that child development interventions are most effective when families and children are directly targeted, when children are younger and disadvantaged, when duration of the intervention is longer and when the intervention is integrated into the sociopolitical context. ${ }^{6}{ }^{29}$ Our interventions attempted to incorporate these elements.

A previous evaluation of 44 children attending the PNWW urban day-care centres concluded that, while providing a safe environment for children, freeing mothers of worries and enabling them to work or study, a positive impact on children's language or motor skills could not be detected. ${ }^{19}$ There are several potential reasons why this evaluation differs from the results of our study: the PNWW delivered to children at day-care centres can only promote mother-child interaction to a limited degree. Furthermore, the previous PNWW evaluation applied a non-randomised design, comparing 'treatment'

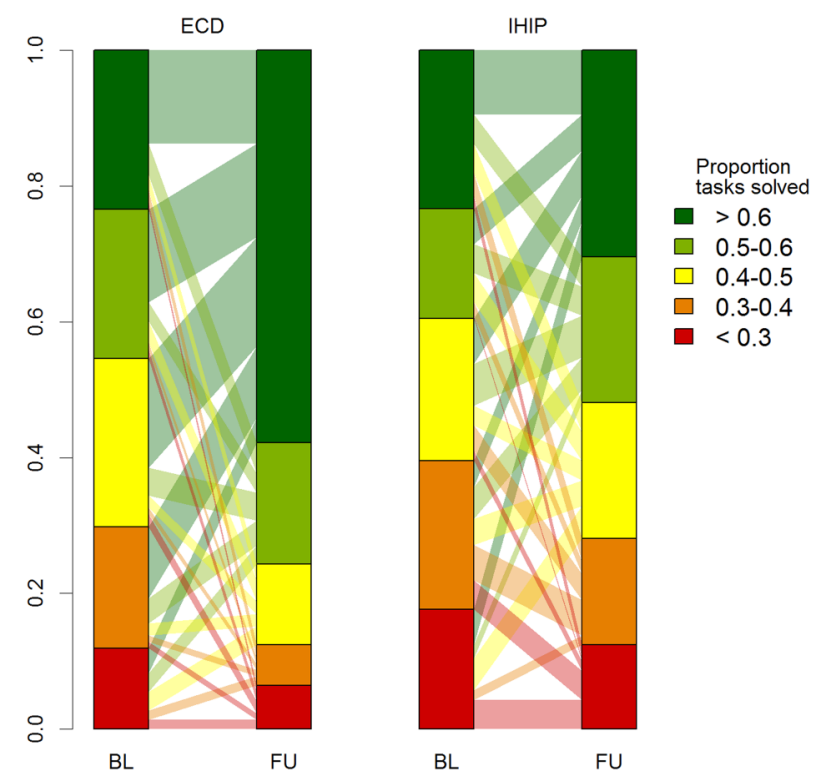

Figure 4 Comparison between children in the EDC and IHIP group showing baseline and final assessment performance in achieving ECD evaluation assessment tasks. Vertical scale represents proportion of children belonging to a certain performance category. BL, baseline; FU, follow-up; ECD, early child development; IHIP, integrated home-based intervention package. Transparent connecting bars show the proportional transfer from the baseline categories to follow-up categories.

children whose parents usually worked with control children whose parents were at home and/or were able to look after them.

Other evidence supports our findings that the home-based approach, tested here for the first time in rural Andean Peru, can be successful in improving ECD. A recent evaluation of an intervention that considered group delivery strategies and home visits adapted from the UNICEF/WHO Care for Child Development programme in Pakistan improved ECD, the home environment, mother-child interaction, mother's mental health, child rearing knowledge and practices and children's health. ${ }^{30}$ A review of home-based interventions from low-income and middle-income countries also found improvements in different ECD al and maternal outcomes. ${ }^{6}$ Another systematic review showed sustained positive development impacts such as

Table 2 Comparison of successfully completed evaluation tasks between ECD-group $(n=219)$ and IHIP-group ( $n=216)$ children after 1-year follow-up

\begin{tabular}{|c|c|c|c|c|c|}
\hline \multirow[b]{2}{*}{ Child developmental domain } & \multicolumn{2}{|l|}{ Proportion indicators solved } & \multicolumn{2}{|l|}{ Scored above mean } & \multirow[b]{2}{*}{$\mathrm{RR}^{*}(95 \% \mathrm{Cl})$} \\
\hline & ECD group, median (IQR) & IHIP group, median (IQR) & ECD group, \% (n) & IHIP group, \% (n) & \\
\hline $\mathrm{FM}$ & $60 \%(25-75)$ & $40 \%(20-60)$ & $62(136)$ & $39(84)$ & $1.6(1.2$ to 2.0$)$ \\
\hline RO & $67 \%(50-75)$ & $50 \%(33-67)$ & $62(135)$ & $40(86)$ & $1.5(1.3$ to 1.9$)$ \\
\hline $\mathrm{BH}$ & $66 \%(50-100)$ & $50 \%(33-67)$ & $57(124)$ & $36(77)$ & $1.6(1.3$ to 2.0$)$ \\
\hline PS & $80 \%(60-100)$ & $60 \%(40-83)$ & $60(131)$ & $40(86)$ & $1.5(1.1$ to 2.0$)$ \\
\hline $\mathrm{CO}$ & $60 \%(40-80)$ & $40 \%(33-60)$ & $54(119)$ & $36(77)$ & 1.5 (1.1 to 2.2$)$ \\
\hline ST & $67 \%(33-75)$ & $50 \%(25-67)$ & $66(145)$ & $49(106)$ & 1.3 (1.0 to 1.8$)$ \\
\hline GM & $67 \%(50-83)$ & $67 \%(50-83)$ & $49(108)$ & $37(80)$ & $1.3(1.0$ to 1.7$)$ \\
\hline
\end{tabular}

${ }^{*}$ Relative risks, estimated by log-binomial generalised estimating equations to account for within-cluster correlation.

$\mathrm{BH}$, basic habits; $\mathrm{CO}$, communication; ECD, early child development; FM, fine motor skills; GM, gross motor skills; IHIP, integrated household intervention package; PS, personal and social development; RO, Relationship between objects; ST, space and time. 
cognitive, language and socioemotional outcomes from early childhood interventions up to adult age. ${ }^{31}$

In our study, children in the ECD group performed better than those in the IHIP group, especially in the domains covering fine motor skills, relationship between objects, basic habits, and personal and social development. These domains are likely to rely more than others on an intensified interaction between the child and the caretaker. Improvements in these domains are also more likely from an intervention specifically employing age-appropriate toys and learning materials for children. Other domains, such as 'gross motor skills' and 'space and time', which are generally expected to develop 'automatically' through daily routines and exploring the surroundings, were significantly improved in the ECD group compared to the IHIP group. We see this as evidence that all seven domains benefit from and require stimulation and do not develop independently from interaction with other people.

\section{Limitations}

Four fieldworkers implemented and evaluated the intervention. Fieldworkers therefore knew which households received the early child intervention, which might have induced bias. We, however, rigorously trained fieldworkers to assess outcomes in a standardised way. Consequently, children knew some of the fieldworkers from their regular home visits. Those children might therefore have interacted differently with the fieldworkers during evaluations of main developmental milestones. However, children in the IHIP group also interacted with the fieldworkers before and during implementation of the environmental intervention package.

Improvements in the PNWW checklist markers do not necessarily reflect sustainable advances in psychomotor or cognitive development. The results do, however, show that children who received the alternative ECD intervention were better equipped to achieve developmental advances while growing up. The clear differences in the seven domains between the two groups support the principal option that long-term tangible development outcomes in the ECD group are possible. Different early child stimulation interventions showed sustained developmental benefits over many years. ${ }^{6} 31$ Further analyses of this child cohort will show if these improvements are sustained and translate into benefits at school age.

Unfortunately, we could not compare our results with national and regional PNWW statistics. Those could not be provided due to governmental and programmatic changes in 2011.

Finally, we cannot rule out that our results are associated with loss to follow-up bias. However, the number of children lost over the 1 year follow-up period was about 15\% (moderate) and balanced in both groups. In addition, children lost did not differ remarkably from the remaining children with respect to baseline performance (see online supplementary table S1).

\section{Strengths}

Our ECD intervention differed from the original PNWW implementation and design in two main aspects that could have had an impact on the study children: (1) the intervention was carried out at household level and (2) the person who directly worked with the parent was a trained professional (former preschool or primary school teacher), which had proved to be an effective approach in past interventions. ${ }^{32} 33$ In our rural setting where we found about three toys per home-a number likely to be a magnitude lower than in urban Peru-we have anecdotal evidence that the intervention had effects on the intervention household and beyond. The toys were shared with neighbouring families and mothers reportedly increased their exchanges on child development issues. ECD programmes, like our adapted version of PNWW, are needed for rural poverty reduction strategies.

To the best of our knowledge, this is the first large-scale, population-based randomised trial in Peru that assessed an early childhood stimulation intervention. The randomised evaluation setting allows us to draw valid conclusions on the impact of this intervention on the study children, even if evaluating the ECD intervention was not the primary objective of the trial. We adapted the nationally developed PNWW programme for urban day cares for application at rural household level and to directly address very young children and their mothers. We aimed to strengthen mother-child relations and to create safe playing and feeding home environments to positively affect ECD. ${ }^{34} 35$ Mothers frequently stated during the ECD training that they felt more engaged with their child and his/her development. This is in line with previous findings of improved selfesteem and mental health among mothers participating in such programmes. $^{30}$

The PNWW checklist is a tool for evaluating all important developmental outcomes and assesses the main child developmental milestones by age. ${ }^{28}$ To maximise comparability with other PNWW national evaluation experiences, we used the PNWW standard evaluation tool for ECD outcomes in our study. This step will support communication of our findings with national programme decision makers and other national stakeholders. Additionally, child developmental milestones were assessed by the direct observation of trained fieldworkers and, thus, were not prone to reporting bias by the caretaker. Project staff conducting the ECD assessments had a professional education and practical exposure as teachers and/or preschool teachers and was from the San Marcos area. They were well accepted in the local environment and were granted full access to homes without exceptions.

Our findings support the latest changes in relevant government policies. The PNWW was restructured in 2011 and places a strong focus through its new programme 'Accompanying the Family', on children younger than 3 years of age and parentchild interaction. The programme is now called 'Cuna Mas' and will deliver early child stimulation at rural and peri-urban household level at scale. ${ }^{36}$

\section{CONCLUSIONS}

This study has demonstrated a significant improvement in seven key development domains among children 6-35 months of age following a child development intervention implemented at household level in underprivileged rural Peru. These domains include fine motor skills, personal and social development, and relationship between objects, thereby generating essential preconditions for sustained improvements in psychomotor and cognitive development. This evidence supports and informs current national development policies and endeavours to expand the outreach of early stimulation programmes to poor rural households as an important part of mitigating inequalities and poverty in rural Andean Peru. 


\section{What is already known on this subject}

- We searched PubMed and Web of Science using the key search terms 'child development', 'infant development', 'motor development', 'skill development', 'cognitive development', 'personal development', 'social development', 'emotional development', 'early education', 'infant education', 'early child', 'child learning', 'language skills', 'cognitive skills', 'social emotional skills', 'motor skills', 'parent child' and 'mother child'. The search yielded a Lancet 2007 series that influenced the original study design and local setup. An updated search following the intervention led to consideration of the Lancet 2011 series and of the systematic reviews by Baker-Henningham and López Bóo ${ }^{6}$ and Grantham-McGregor 2014 GranthamMcGregor SM, Fernando LC, Kagawa RM \& walker S. Effects of integrated child development and nutrition interventions on child development and nutritional status. Ann N Y Acad Sci 2014;1308:11-32. which confirmed our approach and analysis.

- Evidence from the literature suggests that hampered early child development is a global issue that could be prevented by early childhood stimulation interventions, particularly those that directly target disadvantaged children and their families. Our study puts these findings and recommendations into practice in a poor, rural Peruvian setting. The intervention was linked to a national programme to strengthen sustainability.

\section{What this study adds}

- The present study provides evidence that the Wawa Wasi National Programme on early child development (ECD) can be successfully adapted for household-level application in Peru. Findings demonstrate that the intervention group performed significantly better in all developmental domains (including basic habits, personal and social development, gross and fine motor skills, relationship between objects, space and time, and communication skills). In addition to significant improvements in individual child psychomotor and cognitive development, we found strengthened motherchild relationships and enhanced between-household exchanges on child rearing and playing. This finding indicates that the intervention may have a broader positive impact at household, family and community levels.

- The evidence generated by this study supports and validates the newly reconfigured National CUNA MAS programme, which focuses on household-level ECD interventions.

Acknowledgements The authors wish to express their appreciation and thanks to the study families, the local authorities and the National Wawa Wasi Programme coordinators in Cajamarca for their kind participation and continuous support throughout the study. The authors would also like to express their gratitude to the field teams for their hard work. The authors gratefully acknowledge the language editing of Amena Briët, Swiss Tropical and Public Health Institute and the exchanges with the anonymous reviewers.

Contributors DM and CFL obtained the funding. DM, SMH and CFL conceived and designed the study. CFL, SMH, HV and AIG acquired the data. SMH, JW, JH, DM, CFL and MN analysed and interpreted the data. JW, SMH, MOO and JH drafted a first version of the manuscript. All authors critically revised and approved the final version of the manuscript.

Funding Financial support for this study was provided by the UBS Optimus, a Swiss private foundation. The funders of the study had no involvement in study design, data collection, analysis or interpretation of the data, nor were they involved in the writing of this paper or in the decision to submit the paper for publication.

Competing interests None declared.

Ethics approval Nutritional Research Institute, Peru and Swiss Cantonal Ethical Review Board (Ethikkommission Beider Basel, EKBB).

Provenance and peer review Not commissioned; externally peer reviewed.

Open Access This is an Open Access article distributed in accordance with the Creative Commons Attribution Non Commercial (CC BY-NC 4.0) license, which permits others to distribute, remix, adapt, build upon this work non-commercially, and license their derivative works on different terms, provided the original work is properly cited and the use is non-commercial. See: http://creativecommons.org/ licenses/by-nc/4.0/

\section{REFERENCES}

1 WHO. Social determinants of health: early child development. WHO. http://www. who.int/social_determinants/themes/earlychilddevelopment/en/ (accessed 1 Jul 2014).

2 Grantham-McGregor S, Cheung YB, Cueto S, et al. Developmental potential in the first 5 years for children in developing countries. Lancet 2007;369:60-70.

3 Walker SP, Wachs TD, Grantham-McGregor S, et al. Inequality in early childhood: risk and protective factors for early child development. Lancet 2011:378:1325-38.

4 Hertzman C, Boyce T. How experience gets under the skin to create gradients in developmental health. Annu Rev Public Health 2010;31:329-47.

5 Siddiqi A, Hertzman E, Irwin L, et al. Early child development: a powerful equalizer. In: Jennifer H. Lee, Ritu Sadana eds. Improving equity in health by addressing social determinants. World Health Organization: Geneva, Switzerland, 2011:115-41.

6 Baker-Henningham H, López Bóo F. Early childhood stimulation interventions in developing countries: a comprehensive literature review. Rochester (NY): Social Science Research Network, 2010. http://papers.ssrn.com/abstract=1700451 (accessed 7 Feb 2014)

7 Reynolds AJ, Temple JA. Cost-effective early childhood development programs from preschool to third grade. Annu Rev Clin Psychol 2008:4:109-39.

8 Heckman JJ, Masterov DV. The productivity argument for investing in young children. Appl Econ Perspect Pol 2007;29:446-93.

9 Holt RL, Mikati MA. Care for child development: basic science rationale and effects of interventions. Pediatr Neurol 2011;44:239-53.

10 McCartney K, Dearing E, Taylor BA, et al. Quality child care supports the achievement of low-income children: direct and indirect pathways through caregiving and the home environment. J App/ Dev Psychol 2007;28:411-26.

11 Levin AR, Zeanah CHJr, Fox NA, et al. Motor outcomes in children exposed to early psychosocial deprivation. J Pediatr 2014;164:123-9.e1.

12 Araujo M, López Bóo F, Puyana J. Overview of early childhood development services in Latin America and the Caribbean. Inter-American Development Bank, 2013. http://www.iadb.org/en/publications/publication-detail,7101.html?id=70535 (accessed 11 Feb 2014).

13 WHO. World health statistics 2015, Part II, Global health indicators. World Health Organization, 2015

14 Schady N, Behrman JR, Araujo MC, et al. Wealth gradients in early childhood cognitive development in five Latin American countries. J Hum Resour 2015;50:446-63.

15 Programme for International Student Assessment. PISA 2012 results in focus: what 15-year-olds know and what they can do with what they know. PISA, OECD, 2013. http://www.oecd.org/pisa/keyfindings/pisa-2012-results.htm

16 PAHO. Country chapters: Peru. In: Health in the Americas. 2012th edn. 2012 http://www.paho.org/saludenlasamericas/index.php?option=com content\&view=article\&id $=51$ \&ltemid $=44 \&$ lang=en (accessed 6 Jul 2014).

17 Castro J, Rolleston C. Explaining the urban-rural gap in cognitive achievement in Peru: the role of early childhood environments and school influences. Young Lives, 2015.

18 INEI. Censos Nacionales 2007: XI de Población y VI de Vivienda-Cuadros Estadísticos. http://censos.inei.gob.pe/cpv2007/tabulados/ (accessed 28 Jan 2014).

19 Cueto S, Guerrero G, Leon J, et al. Promoting early childhood development through a public programme: Wawa Wasi in Peru. University of Oxford, Department of International Development, Young Lives, 2009. http://www.grade.org.pe/asp/brw _ pub11.asp?id=859 (accessed 5 Mar 2014)

20 Ronfani L, Vecchi Brumatti L, Mariuz M, et al. The complex interaction between home environment, socioeconomic status, maternal IQ and early child neurocognitive development: a multivariate analysis of data collected in a newborn cohort study. PLoS One 2015;10:e0127052.

21 Hartinger SM, Lanata CF, Hattendorf J, et al. A community randomised controlled trial evaluating a home-based environmental intervention package of improved 


\section{Child health}

stoves, solar water disinfection and kitchen sinks in rural Peru: rationale, trial design and baseline findings. Contemp Clin Trials 2011;32:864-73.

22 Hartinger SM, Lanata CF, Gil Al, et al. Combining interventions: improved chimney stoves, kitchen sinks and solar disinfection of drinking water and kitchen clothes to improve home hygiene in rural Peru. Field Actions Sci Rep 2012 (Special Issue 6). http://factsreports.revues.org/1627 (accessed 3 May 2013).

23 Hartinger, et al. Improving household air pollution, drinking water quality and hygiene in rural Peru: a community-randomised controlled trial of an environmental, home-based intervention package. Int J Epidemiol 2016.

24 Moulton LH. Covariate-based constrained randomization of group-randomized trials. Clin Trials 2004;1:297-305.

25 Schmidt W-P, Cairncross S. Household water treatment in poor populations: is there enough evidence for scaling up now? Environ Sci Technol 2009;43: 986-92.

26 Savović J, Jones HE, Altman DG, et al. Influence of reported study design characteristics on intervention effect estimates from randomized, controlled trials. Ann Intern Med 2012;157:429-38.

27 MIMDES. Manual Para La Aplicación Del Instrumento: Lista de Cotejo de Logros Pedagógicos Para Niños Y Niñas Menores de 4 Años. Lima, Peru: Ministerio de la Mujer y Desarrollo Social, 2007.

28 Programa Nacional Wawa Wasi, Sede central. Oficina de Atención Integral, Componente de Apredizaje Infantil Temprano: Manual Para La Aplicación Del Instrumento: Lista de Cotejo de Logros Pedagógicos Para Niñas Y Niños de 6 Meses a 4 Años. Lima, Peru: MIMDES, Ministerio de la Mujer y Desarrollo Social, 2007.
29 Engle PL, Black MM, Behrman JR, et al. Strategies to avoid the loss of developmental potential in more than 200 million children in the developing world. Lancet 2007;369:229-42.

30 Promoting Care for Child Development in Community Health Services, A Summary of the Pakistan Early Child Development Scale-up (PEDS) Trial. New York: UNICEF, 2013. http://www.unicef.org/earlychildhood/files/3_PEDS_Trial_Summary_Report.pdf (accessed 2 Jul 2014).

31 Tanner JC, Candland T, Odden WS. Later impacts of early childhood interventions: a systematic review. Washington: Independent Evaluation Group, World Bank Group, 2015.

32 Eickmann SH, Lima AC, Guerra MQ, et al. Improved cognitive and motor development in a community-based intervention of psychosocial stimulation in northeast Brazil. Dev Med Child Neurol 2003;45:536-41.

33 Domitrovich CE, Cortes RC, Greenberg MT. Improving young children's social and emotional competence: a randomized trial of the preschool "PATHS" curriculum. J Prim Prev 2007;28:67-91.

34 Department of Child and Adolescent Health and Development, WHO. The importance of caregiver-child interactions for the survival and healthy development of young children, a review. World Health Organization, 2004.

35 Ngure FM, Reid BM, Humphrey JH, et al. Water, sanitation, and hygiene (WASH), environmental enteropathy, nutrition, and early child development: making the links. Ann NY Acad Sci 2014;1308:118-28.

36 Programa Nacional Cuna Más. Plan Operativo Institucional-POI 2012 Reformulado. Lima, Peru: MIDIS, 2012. http://www.peru.gob.pe/docs/PLANES/13274/PLAN_13274_ Plan_Operativo_Institucional_2012_Reformulado_2012.pdf (accessed 5 Mar 2014). 